\title{
Increased cholinergic contractions of jejunal smooth muscle caused by a high cholesterol diet are prevented by the $5-\mathrm{HT}_{4}$ agonist - tegaserod
}

\author{
Ronald Mathison*1 and Eldon Shaffer ${ }^{2}$
}

Address: ${ }^{1}$ Department of Physiology and Biophysics, University of Calgary, Calgary, AB, T2N 4N1, Canada and ${ }^{2}$ Department of Medicine, Faculty of Medicine, University of Calgary, Calgary, AB, T2N 4N1, Canada

Email: Ronald Mathison* - Ronald.Mathison@ucalgary.ca; Eldon Shaffer - shaffer@ucalgary.ca

* Corresponding author

Published: 23 February 2006

BMC Gastroenterology2006, 6:8 doi:10.1/86/147|-230X-6-8

This article is available from: http://www.biomedcentral.com//47I-230X/6/8

(c) 2006Mathison and Shaffer; licensee BioMed Central Ltd.

This is an Open Access article distributed under the terms of the Creative Commons Attribution License (http://creativecommons.org/licenses/by/2.0), which permits unrestricted use, distribution, and reproduction in any medium, provided the original work is properly cited.
Received: 05 August 2005

Accepted: 23 February 2006

\begin{abstract}
Background: Excess cholesterol in bile and in blood is a major risk factor for the respective development of gallbladder disease and atherosclerosis. This lipid in excess negatively impacts the functioning of other smooth muscles, including the intestine. Serotonin is an important mediator of the contractile responses of the small intestine. Drugs targeting the serotonin receptor are used as prokinetic agents to manage intestinal motor disorders, in particular irritable bowel syndrome. Thus, tegaserod, acting on $5-\mathrm{HT}_{4}$ receptor, ideally should obviate detrimental effects of excessive cholesterol on gastrointestinal smooth muscle. In this study we examined the effect of tegaserod on cholesterol-induced changes in the contractile responses of intestinal smooth muscle.
\end{abstract}

Methods: The effects of a high cholesterol (I\%) diet on the in vitro contractile responses of jejunal longitudinal smooth muscle from Richardson ground squirrels to the cholinergic agonist carbachol were examined in the presence or absence of tetrodrodotoxin (TTX). Two groups of animals, fed either low $(0.03 \%)$ or high cholesterol rat chow diet, were further divided into two subgroups and treated for 28 days with either vehicle or tegaserod.

Results: The high cholesterol diet increased, by nearly 2-fold, contractions of the jejunal longitudinal smooth muscle elicited by carbachol. These cholinergic contractions were mediated by muscarinic receptors since they were blocked by scopolamine, a muscarinic receptor antagonist, but not by the nicotinic receptor antagonist, hexamethonium. Tegaserod treatment, which did not affect cholinergic contractions of tissues from low cholesterol fed animals, abrogated the increase caused by the high cholesterol diet. With low cholesterol diet TTX enhanced carbachol-evoked contractions, whereas this action potential blocker did not affect the augmented cholinergic contractions seen with tissues from animals on the high cholesterol diet. Tegaserod-treatment removed the effects of a high cholesterol diet on neuronal muscarinic receptors, as the potentiating effect of TTX on carbachol-elicited contractions was maintained in these animals.

Conclusion: A high cholesterol diet causes significant changes to cholinergic neurotransmission in the enteric nerves of the jejunum. The mechanisms by which these effects of cholesterol are reversed by tegaserod are unknown, but relate to removal of an inhibitory effect of cholesterol on enteric nerves. 


\section{Background}

In cholesterol gallstone formation, gallbladder smooth muscle develops reduced contractions, and the resulting impaired emptying leads to stasis. This dysfunction retains the cholesterol crystals that have nucleated from the supersaturated bile; the microcrystals agglomerate and stone growth follows $[1,2]$. Patients with gallstones also exhibit delayed small intestinal [3] and colonic [4] transit, which results in decreased enterohepatic cycling of bile salts [5] and so increases deoxycholic acid formation from cholic acid [6]. The deoxycholic acid and the reduced enterohepatic cycling adversely influence hepatic bile salt and cholesterol secretion and contribute to the formation of bile supersaturated with cholesterol.

A participatory role of the intestine in gallstone formation has also been established in animal models of gallbladder disease. The Richardson ground squirrel and the prairie dog on a high cholesterol diet develop lithogenic bile containing excess cholesterol relative to its solubilizing capacity $[7,8]$. Smooth muscle function of these animals is altered negatively: their gallbladders exhibit reduced contractile responses to CCK8 and acetylcholine [8], while small intestine transit and the cycle period of migrating myoelectric complexes are prolonged $[9,10]$. The basis for these intestinal motility changes is unknown, but might relate to the excess biliary cholesterol excreted into the duodenum and/or the hypercholesterolemic state of the animal model fed a high cholesterol diet.

From a therapeutic perspective, "prokinetic" agents, such as indoramin, an alpha-adrenergic antagonist, cisapride, a 5- $\mathrm{HT}_{4}$-agonist/5- $\mathrm{HT}_{3}$-antagonist, and erythromycin, a motilin agonist, promote small and large bowel transit, and enhance gallbladder emptying and so hinder gallstone formation $[10,11]$. In Richardson ground squirrels, cisapride reverses the defect in gallbladder contractility, enhances bile salt secretion and lowers cholesterol saturation [11]. Since cisapride is now known to cause cardiac rhythm disturbances [12], a new prokinetic agent, tegaserod, a partial 5- $\mathrm{HT}_{4}$-agonist [13], which enhances peristalsis, was approved for the treatment of patients exhibiting symptomatic irritable bowel syndrome (IBS) with constipation. IBS generally is associated with an increased risk of abdominal surgery, including cholecystectomy [14]. Hence, drugs used to treat this condition should not adversely affect gallbladder function. In a recent human study, tegaserod did not alter gallbladder contractility or the diameter of the common bile and hepatic ducts [15]. Nonetheless, the effects of tegaserod on small bowel function when there is a predisposition to gallstone formation are not known.

Since serotonin agonists contribute to the contractile responses of the small intestine $[16,17]$ and are used to manage intestinal motor disorders $[18,19]$, we postulated that tegaserod would modify cholesterol-induced changes in the contractile responses of intestinal smooth muscle. To test this hypothesis we examined the effects of tegaserod on cholinergic-induced contractions of the longitudinal smooth muscle of jejunal and ileal tissues obtained from Richardson ground squirrels that were maintained for 28 days on either a low $(0.03 \%)$ or a high $(1 \%)$ cholesterol diet.

\section{Methods \\ Experimental animals}

The University of Calgary Animal Care Committee approved the research protocol, which conforms to the guidelines of the Canadian Council on Animal Care. 76 Richardson ground squirrels (Spermophilus richardsoni) were trapped wild near Calgary, Alberta and were given ivermectin (Merial Canada Inc., Baie d'Urfé, QC, Canada) shortly after capture to eliminate nematode parasites. The animals were acclimatized for a minimum period of four weeks by caging them individually in thermoregulated rooms on a $12 \mathrm{~h} / 12 \mathrm{~h}$ day/night light cycle with free access to a standard rat chow diet. Most animals adjusted well to captivity and gained weight, but 4 (7\%) of them did not thrive or gain weight and were excluded from the study. After acclimatization, the animals were fed, under the same holding conditions for an additional four weeks, either a low cholesterol (normal) diet (0.03\%, Dyets Inc., Bethlehem, PA, USA) or a high cholesterol diet (Dyets Inc.), comprising an identical chow enriched with $1 \%$ cholesterol by weight. During this diet period the animals were injected subcutaneously, twice daily, with either vehicle or $0.1 \mathrm{mg} / \mathrm{kg}$ of tegaserod (kindly supplied by Novartis Pharma, Basel, Switzerland). Tegaserod was dissolved in vehicle (100\% 1-methyl-2-pyrrolidinone) immediately before use, and then diluted into $154 \mathrm{mM}$ $\mathrm{NaCl}$ such that the final concentration of 1-methyl-2-pyrrolidinone was $2.7 \%$. The vehicle-treated animals received 2.7\% 1-methyl-2-pyrrolidinone (Sigma-Aldrich, St. Louis, $\mathrm{MO}$, USA) in $154 \mathrm{mM} \mathrm{NaCl}$. The animals were randomly divided into four groups, with 18 in each group and received the following combination of diet and drug: (1) vehicle + low cholesterol diet, (2) vehicle + high cholesterol diet, (3) tegaserod + low cholesterol diet, and (4) tegaserod + high cholesterol diet. The treatments were organized so that 2 animals from any one treatment group were used for experiments 28 days later. Gallbladder and hepatic bile cholesterol concentration and intestinal contractility were measured with all animals.

\section{Cholesterol concentrations in hepatic and gallbladder bile} For collection of common duct bile animals were fasted for 14 hours, and then anesthetized and maintained on a low concentration (1.5 to 2\%) isoflurane (Ayerst Laboratories, Montreal, QC, Canada). At laparotomy the cystic 
duct was exposed and ligated, the gallbladder removed and the bile collected for subsequent analysis. The common bile duct was cannulated with a polyethylene catheter (PE50), and hepatic bile was collected for two onehour periods. During this period $154 \mathrm{mM} \mathrm{NaC1}$ was infused continuously IV at $2.5 \mathrm{~mL} / \mathrm{h}$ via a femoral venous cannula for fluid replacement.

Cholesterol was measured using the Liebermann-Burchard reaction (Cholesterol/Cholesteryl Ester Quantitation $\mathrm{Kit}^{\mathrm{TM}}$ of Biovision; Mountain View, CA, USA).

\section{Intestinal contractility in vitro}

At the end of the collection period for hepatic bile the intestine was removed to evaluate contractile responses of smooth muscle [9]. Four $2 \mathrm{~cm}$ lengths of intestine were obtained in each animal, two from the proximal jejunum at a point $5 \mathrm{~cm}$ distal to the ligament of Treitz, and two from the distal ileum at a location $15 \mathrm{~cm}$ proximal to the ileocecal valve. Without occluding the lumen, 5-0 silk threads were tied to opposite ends of each segment with one end fixed to the bottom of a $20 \mathrm{~mL}$ organ bath, and the other to an isometric force-displacement transducer (FT03; Grass Telefactor, West Warwick, RI, USA)). This montage measured the contractile response of the longitudinal smooth muscle layer. The baths, maintained at a temperature of $35^{\circ} \mathrm{C}$, were filled with a modified Krebs solution of the following composition (in $\mathrm{mM}$ ): $\mathrm{NaC} 1$ 103, $\mathrm{KC} 14.7, \mathrm{MgC1}_{2} 1.13, \mathrm{NaHCO}_{3} 25, \mathrm{NaH}_{2} \mathrm{PO}_{4}$ 1.15, $\mathrm{CaCl}_{2} 2.56$, D-glucose 2.8 , sodium pyruvate 4.9 , sodium fumarate 2.7, and sodium glutamate 4.9: at $\mathrm{pH}$ 7.4, continuously gassed with a mixture of $95 \% \mathrm{O}_{2}$ and $5 \% \mathrm{CO}_{2}$.

The tissues were stretched to $1 \mathrm{gm}$ of tension, and equilibrated for $40 \mathrm{~min}$ with a change of physiological buffer every $10 \mathrm{~min}$, and appropriate adjustment of tension. After equilibration, the longitudinal intestinal segments underwent cumulative dose-responses $\left(10^{-8} \mathrm{M}\right.$ to $\left.10^{-4} \mathrm{M}\right)$ to carbamylcholine chloride (carbachol; Sigma-Aldrich), performed either in the presence or absence of either 10${ }^{7} \mathrm{M}$ tetrodotoxin (TTX; Sigma-Aldrich), or $10^{-5} \mathrm{M}$ hexamethonium (Sigma-Aldrich). The TTX permitted evaluation of smooth muscle contractility in the absence of neural influences, and hexamethonium, a selective nicotinic antagonist, was used to determine the contribution of nicotinic receptors to the increased tone. With each animal a jejunal or ileal segment was preincubated with either TTX or hexamethonium for $10 \mathrm{~min}$, whereas the other untreated segments served as carbachol controls. Scopolamine was added to the tissues after completion of the cumulative dose-response for carbachol in all animals groups. At the end of each experiment, the tissue preparations were lightly blotted and weighed. The contractile response for each preparation was calculated as stress (Newtons $/ \mathrm{m}^{2}$ ), normalized to the cross-sectional area of the longitudinal smooth muscle layer as previously described [9].

\section{Data analysis}

The results are presented as the mean \pm SEM. The statistical functions used that associated with Excel (Microsoft Office XP, Redmond, WA, USA). Comparisons between the different concentrations of carbachol for two groups were made using the unpaired Student's t-test. With cholesterol measurements one-way analysis of variance was applied, with the differences between groups identified using the unpaired Student's t-test. Statistical values reaching probabilities of $\mathrm{p}<0.05$ were considered significant.

\section{Results \\ Bile cholesterol}

For vehicle-treated animals on a low cholesterol diet the concentration of cholesterol in gallbladder and hepatic duct bile were $2.84 \pm 0.37(\mathrm{n}=14)$ and $0.85 \pm 0.14(\mathrm{n}=$ 12) $\mathrm{mM}$, respectively. Tegaserod treatment of low cholesterol diet animals did not modify cholesterol concentrations in the gallbladder $(2.83 \pm 0.38 \mathrm{mM} ; \mathrm{n}=14)$ or the hepatic duct $(0.67 \pm 0.11 \mathrm{mM} ; \mathrm{n}=13)$ relative to vehicletreated animals. Feeding the animals a high cholesterol diet for 28 days significantly increased the bile cholesterol concentrations to $4.33 \pm 0.47(\mathrm{n}=15)$ and $1.91 \pm 0.30(\mathrm{n}$ $=14) \mathrm{mM}$ in the gallbladder and hepatic duct, respectively. Treating animals on the high cholesterol diet with tegaserod did not modify cholesterol concentration in gallbladder bile ( $4.04 \pm 0.58 \mathrm{mM} ; \mathrm{n}=14)$, but reduced it in hepatic duct bile $(1.29 \pm 0.19 \mathrm{mM} ; \mathrm{n}=13)$ to concentrations significantly lower than that seen in the vehicletreated, high cholesterol animals. These concentrations of hepatic duct bile were higher than those seen with tegaserod-treated, low cholesterol animals.

\section{Phasic and tonic contractions of intestinal segments}

Relative to control animals neither the high cholesterol diet nor the tegaserod treatment, alone or in combination, modified basal and carbachol-induced changes in the phasic contractions of the jejunal and ileal segments. In addition, neither TTX nor hexamethonium altered the phasic contractile activity of the intestinal tissues in any of the animal groups. However, as discussed in the following sections tonic contractile responses to cholinergic stimulation with carbachol where significantly altered by the cholesterol diet and tegaserod treatment, and these alterations were further modified by TTX and hexamethonium.

\section{Cholinergic contractions of jejunal longitudinal smooth muscle}

Isolated jejunal segments from the ground squirrels on a low cholesterol diet responded in a dose-dependent manner to carbachol with increasing tonic contractions to a maximal force of $2.1 \pm 0 . \times 10^{2}$ Newtons $/ \mathrm{m}^{2}$ at $10^{-4} \mathrm{M}$ car- 


\section{Effect of Cholesterol Diet}
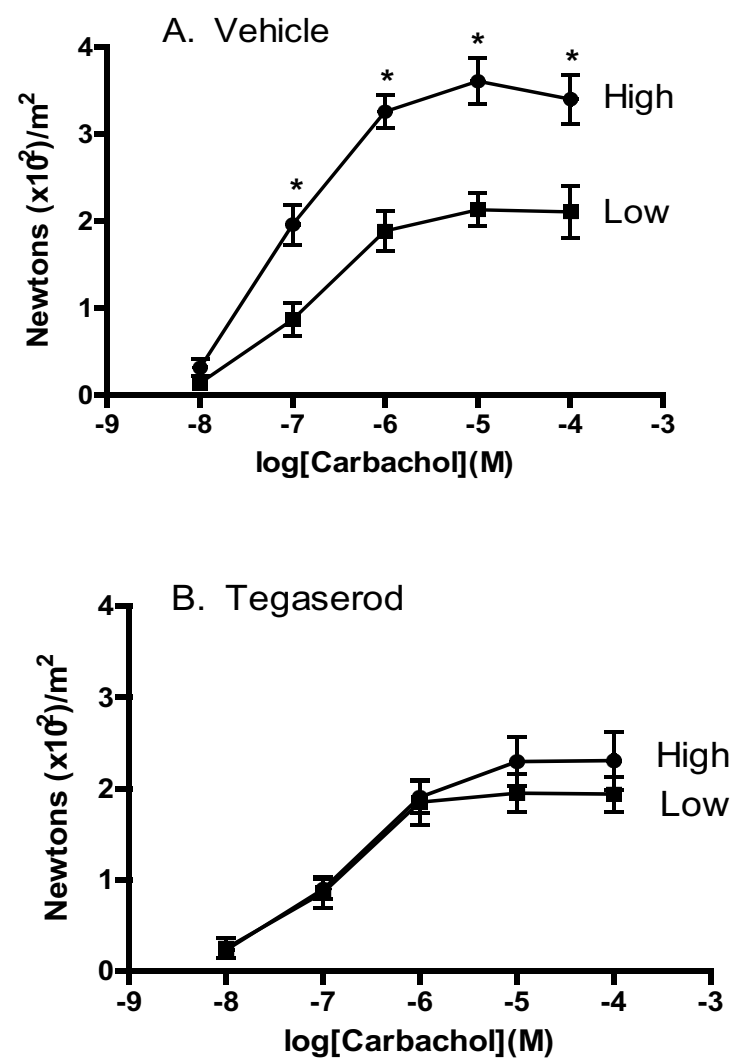

Figure I

Cholesterol diet and cholinergic contractions of the longitudinal muscle of the jejunum. Effects of cholesterol diet on cholinergic (carbachol) - elicited contractions of the jejunum for ground squirrels on a trace $(0.027 \%$; Low) vs. enriched (I\%; High) cholesterol diet for animals treated with either vehicle $(A)$ or tegaserod $(B)$. Cumulative doseresponse curve to carbachol were constructed. * High greater than Low $(P<0.05) ; N=8-9$.

bachol (Figure 1A). In contrast, animals on the high cholesterol diet receiving the vehicle exhibited significantly greater responses to concentrations of carbachol of $10^{-7} \mathrm{M}$ and higher, and showed a maximal response of $3.6 \pm 0.3$ $\left(\times 10^{2}\right)$ Newtons $/ \mathrm{m}^{2}$.

After 4 weeks of tegaserod treatment of animals on a low cholesterol diet, $10^{-4} \mathrm{M}$ carbachol generated a maximal force of $1.9 \pm 0.2 \times 10^{2} \mathrm{Newtons} / \mathrm{m}^{2}$ (Figure $1 \mathrm{~B}$ ), which was similar to the response in vehicle-treated animals. In contrast, jejunal tissues from tegaserod-treated animals on the high cholesterol diet did not exhibit any heightened contractions to carbachol; the maximal response of $2.3 \pm$
$0.3 \times 10^{2}$ Newtons $/ \mathrm{m}^{2}$ was $60 \%$ smaller than that seen with vehicle-treated animals on the high cholesterol diet.

\section{Effect of action potential blockade on carbachol-evoked contractions}

To determine if the cholinergic contractions of the jejunal longitudinal smooth muscle had a neural component, contractions of jejunal smooth muscle were measured after the addition of TTX, a blocker of action potential conduction. In the presence of TTX the dose-response relationships to carbachol on tissues from the vehicle-treated animals on a low cholesterol diet increased approximately 2-fold to $4.4 \pm 0.4\left(\times 10^{2}\right)$ Newtons $/ \mathrm{m}^{2}$ (Figure $2 \mathrm{~A}$ ). Thus, the carbachol-produced contractions of jejunal smooth muscle reflects the net action of two processes; a direct contractile action on smooth muscle, and a relaxation/ inhibition caused by activation of intramural nerves, a process abrogated by TTX. Since the nicotinic receptor antagonist, hexamethonium, did not increase carbacholelicited contractions (Figure $3 \mathrm{~A}$ ), the potentiation of the cholinergic contractions after TTX exposure was independent of neuronal nicotinic receptors. Scopolamine, a muscarininc antagonist, used at a concentration of $10^{-5} \mathrm{M}$, totally blocked the contractile actions of carbachol (data not shown), and also abolished spontaneous contractions.

Animals on the low cholesterol diet treated with tegaserod, like the vehicle-treated controls, exhibited increased contractile responses to carbachol in the presence of TTX (Figure 2C). Hexamethonium did not modify carbacholelicited contractions (Figure $3 \mathrm{~B}$ ). As before, scopolamine $\left(10^{-5} \mathrm{M}\right)$ totally blocked any contractile response to carbachol (not shown). Thus, with tegaserod treatment carbachol contractions of jejunal smooth muscle from low cholesterol diet animals also reflects the net action of two processes; a direct contractile action on smooth muscle and a relaxant action caused by activation of intramural nerves.

Ileal contractions elicited by carbachol were not modified by the high cholesterol diet (Figure 4A), TTX (Figure 4B) or hexamethonium (not shown), indicating that nervedependent potentiation of smooth muscle contractions to carbachol occurred exclusively in the jejunum. Consequently, only the contractile responses to the jejunum are presented.

\section{Interactions between cholinergic contractions, action potential blockade and a high cholesterol diet}

In contrast to the animals on the low cholesterol diet, cholinergic contractions of tissues from animals on the high cholesterol diet were not potentiated after exposure to TTX (Figure 2B). Since carbachol contractions, in the presence of TTX, were of a similar magnitude in tissues 


\section{Effect of Tetrodotoxin}

\section{Vehicle Treatment}
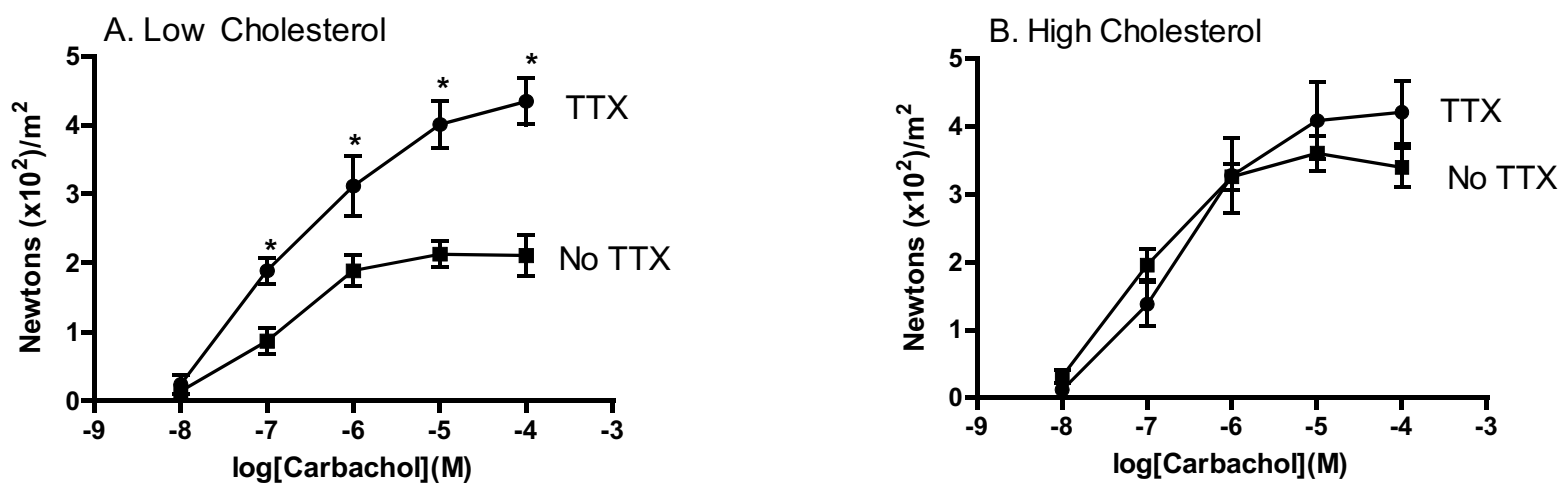

\section{Tegaserod Treatment}
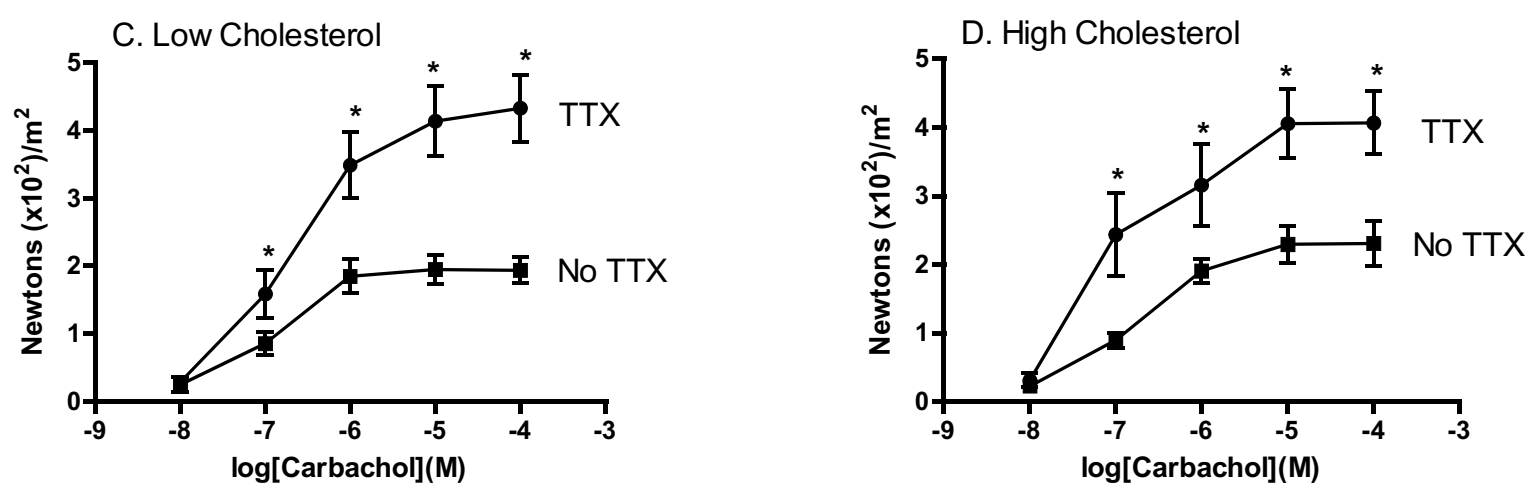

Figure 2

Action potential blockade and contractions of the longitudinal muscle of the jejunum. Effects of tetrodotoxin (TTX) on cholinergic contractions of the jejunum of ground squirrel fed either a low $(0.027 \%$; A \& C) or a high (I\%; B \& D) cholesterol diet. The animals were treated with either vehicle (A \& B) or tegaserod (C \& D). The action potential blocker tetrodotoxin (TTX; 10-7M) was added to the jejunal tissue segments 10 min before constructing a cumulative dose-response curve to the cholinergic agonist, carbachol. * TTX greater than No TTX $(P<0.05) . N=8-9$. 


\section{Nicotinic Receptor Blockade}
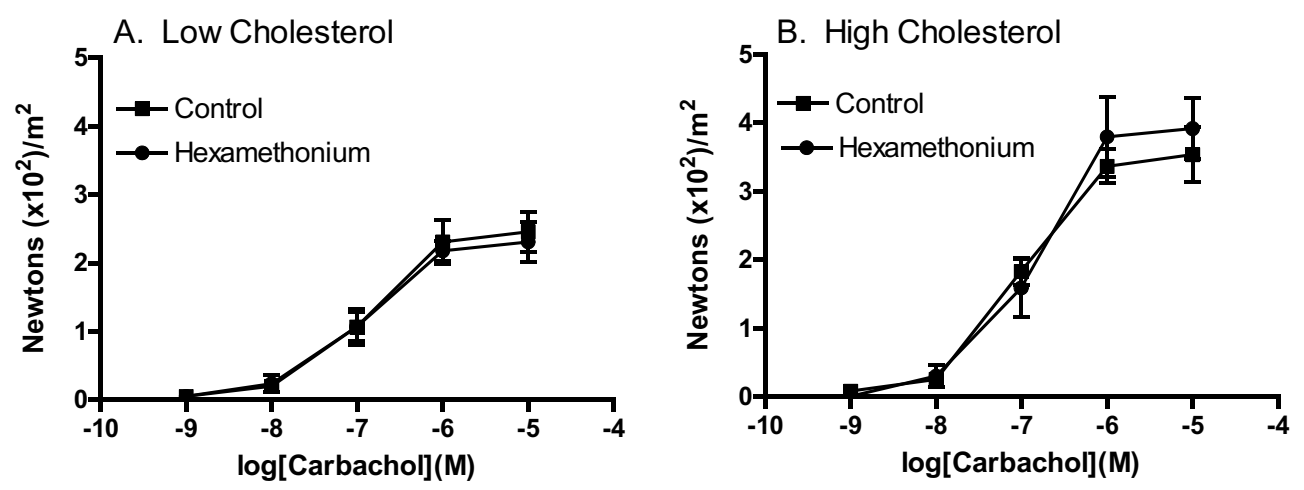

Figure 3

Antagonism of nicotinic receptors and contractions of the longitudinal muscle of the jejunum. Absence of an effect of the nicotinic receptor antagonist, hexamethonium $\left(10^{-5} \mathrm{M}\right)$ on cholinergic contractions of the jejunum of vehicle-treated ground squirrel fed either a low $(0.027 \%$; $A)$ or a high (I\%; B) cholesterol diet. Hexamethonium was added to the jejunal tissue segments $10 \mathrm{~min}$ before constructing a cumulative dose-response curve to the cholinergic agonist, carbachol. $\mathrm{N}=5-6$.

obtained from both low and high cholesterol diet animals, the high cholesterol diet probably increases carbachol-induced contractions by removing a cholinergic neurally-mediated inhibition of tonic smooth muscle contractions. This inhibition is muscarinic receptor-mediated since hexamethonium did not alter carbacholevoked contractions, even in cholesterol-fed animals (Figure $3 \mathrm{~B})$.

For animals on a high cholesterol diet and treated with tegaserod a significant potentiation of the carbachol-elicited contractions was seen following exposure to TTX (Figure 2D). This potentiation is comparable to that seen with tissues from low cholesterol diet animals receiving either vehicle or tegaserod. Thus, tegaserod treatment restores a component of carbachol that was abrogated by the high cholesterol diet.

\section{Discussion}

This study reveals that a high cholesterol diet, fed for 28 days, modifies the properties of cholinergic contractions of jejunal smooth muscle through modulation of cholinergic receptors located on enteric nerves. This action of the high cholesterol diet was prevented by treating the animals with tegaserod.

A high cholesterol diet has diverse effects on cholinergicmediated smooth muscle contractions of different tissues.
With few exceptions [20] a high cholesterol diet is reported to decrease, consequent to gallstone formation [21], the contractile responses of gallbladder smooth muscle to acetylcholine receptor activation in human [21], dog [22] and ground squirrels [8,9]. Few studies have examined the effects of a high cholesterol diet on intestinal smooth muscle contractions, but for the ileum either no effect [[8]; this study Figure 4], or increased contractions [9] have been reported. With the jejunum a high cholesterol diet increases smooth muscle contractile responses to cholinergic agonists [9], and the present study suggests that dietary cholesterol inhibits neuronal muscarinic receptors in the jejunum, allowing for expression of enhanced direct muscarininc receptor stimulatedcontractions of smooth muscle. The reasons for differential responses of jejunal and ileal smooth muscle to cholinergic stimulation are not known, but differences in the local luminal concentrations of cholesterol metabolites known to modify cholinergic receptors may be an underlying cause. Taurocholate, which impairs cholinergic contractions of the gallbladder $[23,24]$ is four times more concentrated in gallbladder bile than in hepatic bile [25]. The glycine and taurine conjugates of deoxycholic acid act as cholinergic muscarinic receptor antagonists [26], and their concentrations are possibly increased in the hepatic bile of cholesterol-fed animals. The absence of an effect of the high cholesterol diet on cholinergic responses in the ileum may reflect reduced concentrations 
lleal Responses
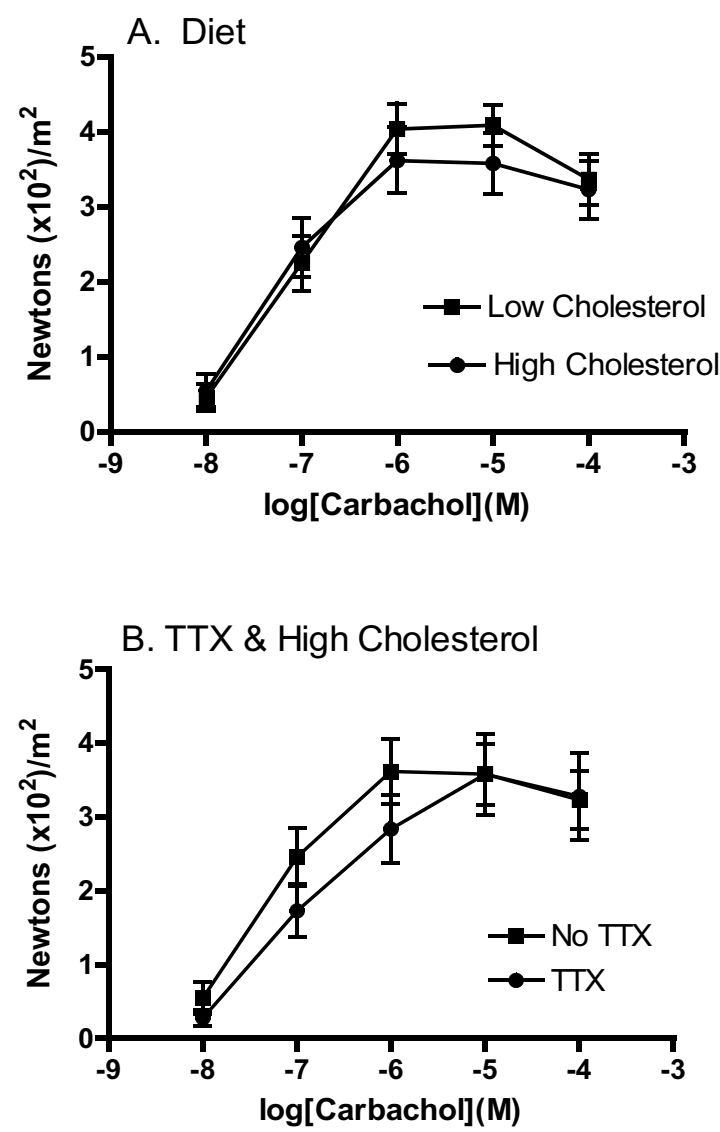

Figure 4

Cholinergic contractions of ileal longitudinal smooth muscle in response to a high cholesterol diet and action potential blockade. (A) Effects of cholesterol diet on cholinergic (carbachol) - elicited contractions of the ileum for ground squirrels on a trace $(0.027 \%$; Low) vs. enriched (I\%; High) cholesterol diet for animals treated with vehicle. (B) Effects of tetrodotoxin (TTX) on cholinergic contractions of the ileum of ground squirrels fed a high (I\%) cholesterol diet and treated with vehicle. The action potential blocker tetrodotoxin (TTX; 10-7M) was added to the jejunal tissue segments 10 min before constructing a cumulative dose-response curve to the cholinergic agonist, carbachol. $\mathrm{N}=8-9$.

of cholinergic modifying bile salts consequent to their enhanced absorption by the ileum relative to the jejunum [27].

Cholesterol is an essential membrane component serving as a cofactor for signalling molecules and as a precursor for steroid hormones. Cholesterol influences many of the biophysical properties of membranes, and depending on the receptor, cholesterol influences the affinity, binding capacity and signal transduction [28]. When inappropriately regulated or excessive, by altering plasma membrane structure-function, cholesterol can play a crucial role in many diseases [28]. Cholesterol's participation in cardiovascular disease is well established, and some neurological [29], immunological [30,31] and gastrointestinal disorders have cholesterol-related components. Cholesterol also has established roles in gallbladder disease [21,32] and modifies other gastrointestinal functions. Although acute exposure to cholesterol decreases pressure in rabbit intestinal loops [33] and reduces nitrergic relaxation of the rabbit sphincter of Oddi muscle [34], most cholesterol-related abnormal events probably result from prolonged exposure to this lipid, and its associated metabolites. In the current study animals were fed a high cholesterol diet for 28 days as with previous studies [9-11], but the time course for the modification of cholinergic receptor function by the cholesterol diet is not known, and acute effects cannot be excluded.

A nervous system-dependent component to cholinergic agonist contractions of the intestinal tissues from Richardson ground squirrels was revealed. Since TTX removed an inhibitory component of cholinergic contractions of the jejunum from animals on a low cholesterol diet (Figures $2 \mathrm{~A}$ and 2C), a part of carbachol-elicited contractions, in low cholesterol dieted animals, are neuronally mediated. Given that carbachol is a mixed muscarinic-nicotinic receptor agonist [35], the neuronal component to cholinergic contractions could be mediated by either nicotinic or muscarininc receptors on neurons and nerve terminals [36-41]. Since hexamethonium, unlike TTX, did not modify carbachol contractions (Figure $1 \mathrm{~B}$ ) the potentiation of the carbachol-elicited contractions did not involve nicotinic receptors, but rather neuronal muscarinic receptors. This modulation by TTX of carbachol-elicited contractions was not evident in the ileum (Figure 4B), and thus either neuronal muscarinic receptors are absent, or possibly obscured, in this intestinal segment by the simultaneous activation of inhibitory and stimulatory receptors, or, as discussed above, the cholesterol metabolites causing the changes in the jejunum are not present in sufficient concentrations in the more distal segments of the small intestine.

In the small intestine $5-\mathrm{HT}_{4}$ receptors, targets for tegaserod action are found exclusively on enteric nerves [43]. The $5-\mathrm{HT}_{4}$ receptors, localized to cholinergic nerves, are involved in the contraction of smooth muscle from canine small and large intestines $[43,44]$ and human large intestines [43]. Mucosal release of 5-HT with activation of $5-\mathrm{HT}_{4}$ receptors on sensory neurons that relay via enteric interneurons to cholinergic motor neurons regulates the peristaltic reflex [45-48]. The rationale for the therapeutic 
use of agents acting at $5-\mathrm{HT}_{4}$ receptors to modulate visceral hypersensitivity supposes that continuous mucosal stimuli cause auto-inhibition and desensitization of 5$\mathrm{HT}_{4}$ receptors [49], and intramural sensory pathways [50]. We did not investigate this sensory-effecter pathway for smooth muscle activation, but rather we examined, using a regimen of drug administration used therapeutically, the actions of tegaserod on cholinergic receptor activation with carbachol. This 28 day treatment with tegaserod removed the potentiating effects of cholesterol diet on cholinergic contractions of the jejunum (Figure 1B) due to the masking of enteric nerve dependent-mediated inhibition of jejunal contractions (Figures 1B and 2D). These effects of tegaserod may also have contributions from unexplored variables such as changes in cholesterol metabolism and contraction-dependent reflex-induced release of 5-HT from enteric nerves.

\section{Conclusion}

Maintaining ground squirrels on a high cholesterol diet for 4 weeks resulted in the removal of an enteric nervous system-dependent, muscarinic suppression of cholinergic contractions of jejunal smooth muscle. This cholesterolmediated inhibition of muscarinic neuronal transmission was prevented by tegaserod, a 5- $\mathrm{HT}_{4}$-partial agonist.

\section{Abbreviations}

5-HT - serotonin; CCK8 - cholecystokinin-octapeptide; CSI - cholesterol saturation index; IBS - irritable bowel syndrome; TTX - tetrodotoxin

\section{Competing interests}

The author(s) declare that they have no competing interests.

\section{Authors' contributions}

All authors participated in study design and read and approved the final manuscript. ES initiated the study and developed the protocol. RM coordinated the study, performed experiments, analyzed the data with statistical analysis and prepared the manuscript in conjunction with ES.

\section{Acknowledgements}

This study was supported by an unrestricted grant from Novartis Pharma AG. The technical support of Robert Kroeker and Chiyuan Li is appreciated.

\section{References}

I. Zapata R, Severin C, Manriquez M, Valdivieso V: Gallbladder motility and lithogenesis in obese patients during diet-induced weight loss. Dig Dis Sci 2000, 45:42I-428.

2. Portincasa P, Di Ciaula A, vanBerge-Henegouwen GP: Smooth muscle function and dysfunction in gallbladder disease. Curr Gastroenterol Rep 2004, 6: I5 I- 162.

3. Azzaroli F, Mazzella G, Mazzeo C, Simoni P, Festi D, Colecchia A, Montagnani M, Martino C, Villanova N, Roda A, Roda E: Sluggish small bowel motility is involved in determining increased bil- iary deoxycholic acid in cholesterol gallstone patients. $\mathrm{Am} \mathrm{J}$ Gastroenterol 1999, 94:2453-2459.

4. Lewis SJ, Heaton KW: The metabolic consequences of slow colonic transit. Am J Gastroenterol 1999, 94:2010-2016.

5. Hardison WG, Tomaszewski N, Grundy SM: Effect of acute alterations in small bowel transit time upon the biliary excretion rate of bile acids. Gastroenterology 1979, 76:568-574.

6. Marcus SN, Heaton KW: Intestinal transit, deoxycholic acid and the cholesterol saturation of bile - three inter-related factors. Gut 1986, 27:550-558.

7. Brenneman DE, Connor WE, Forker EL, DenBesten L: The formation of abnormal bile and cholesterol gallstones from dietary cholesterol in the prairie dog. J Clin Invest 1972, 5 I:1495-503.

8. Fridhandler TM, Davison JS, Shaffer EA: Defective gallbladder contractility in the ground squirrel and prairie dog during the early stages of cholesterol gallstone formation. Gastroenterology 1983, 85:830-836.

9. Xu QW, Scott RB, Tan DT, Shaffer EA: Slow intestinal transit: a motor disorder contributing to cholesterol gallstone formation in the ground squirrel. Hepatology 1996, 23:1664-1672.

10. Xu QW, Scott RB, Tan DT, Shaffer EA: Effect of the prokinetic agent, erythromycin, in the Richardson ground squirrel model of cholesterol gallstone disease. Hepatology 1998, 28:613-619.

II. Xu QW, Shaffer EA: Cisapride improves gallbladder contractility and bile lipid composition in an animal model of gallstone disease. Gastroenterology 1993, 105:1184-1191.

12. Kaumann AJ: Do human atrial 5-HT4 receptors mediate arrhythmias? Trends Pharmacol Sci 1994, I 5:45 I-455.

13. Nguyen A, Camilleri M, Kost LJ, Metzger A, Sarr MG, Hanson RB, Fett SL, Zinsmeister AR: SDZ HTF 919 stimulates canine colonic motility and transit in vivo. J Pharmacol Exp Ther 1997, 280:1270-1276

14. Longstreth GF, Yao JF: Irritable bowel syndrome and surgery: a multivariable analysis. Gastroenterology 2004, I 26:1665-1673.

15. Fisher RS, Thistle J, Lembo A, Novick J, O'Kane P, Chey WD, Beglinger C, Rueegg P, Shi V, Dogra A, Luo D, Earnest DL: Tegaserod does not alter fasting or meal-induced biliary tract motility. Am J Gastroenterol 2004, 99: 1342-1349.

16. Gershon MD: Serotonin and its implication for the management of irritable bowel syndrome. Rev Gastroenterol Disord 2003, 3(Suppl 2):S25-34.

17. Yamamoto I, Kuwahara A, Fujimura M, Kadowaki M, Fujimiya M: Involvement of 5-HT3 and 5-HT4 receptors in the motor activity of isolated vascularly perfused rat duodenum. Neurogastroenterol Motil 1999, I I:457-465.

18. Katschinski M, Schirra J, Begliner C, Langbein S, Wank U, D'Amato M, Arnold R: Intestinal phase of human antro-pyloro-duodenal motility: cholinergic and CCK-mediated regulation. Eur J Clin Invest 1996, 26:574-583.

19. Schoenfeld P: Review article: the safety profile of tegaserod. Aliment Pharmacol Ther 2004, 20(Suppl 7):25-30.

20. Ono K, Nakayoshi A, Suzuki K, Scott GW, Clanachan AS: Gallbladder contractility and gallstone formation in the Richardson Ground Squirrel. Gastroenterol Jpn 1990, 25:93-103.

2I. Behar J, Lee KY, Thompson WR, Biancani P: Gallbladder contraction in patients with pigment and cholesterol stones. Gastroenterology 1989, 97:1479-1484.

22. Mansour A, Dawoud I, Gad-El-Hak N: The potential site of disordered gallbladder contractility during the early stage of cholesterol gallstone formation. Hepatogastroenterology 1998, 45: 1 404-। 409.

23. Xu QW, Freedman SM, Shaffer EA: Inhibitory effect of bile salts on gallbladder smooth muscle contractility in the guinea pig in vitro. Gastroenterology 1997, I I 2:1699-1706.

24. Stolk MF, Van de Heijning BJ, Van Erpecum KJ, Verheem A, Akkermans LM, Van Berge-Henegouwen GP: Effect of bile salts on in vitro gallbladder motility: preliminary study. Ital J Gastroenterol 1996, 28:105-III.

25. Booker ML, LaMorte WW, Beer ER, Hopkins SR: Effects of dietary cholesterol and triglycerides on lipid concentrations in liver, plasma, and bile. Lipids 1997, 32:163-172.

26. Raufman JP, Chen Y, Zimniak P, Cheng K: Deoxycholic acid conjugates are muscarinic cholinergic receptor antagonists. Pharmacology 2002, 65:215-22I. 
27. Lewis $M C$, Root $C$ : In vivo transport kinetics and distribution of taurocholate by rat ileum and jejunum. Am J Physiol 1990, 259:G233-238.

28. Burger K, Gimpl G, Fahrenholz F: Regulation of receptor function by cholesterol. Cell Mol Life Sci 2000, 57:1577-1592.

29. Puglielli L, Tanzi RE, Kovacs DM: Alzheimer's disease: the cholesterol connection. Nat Neurosci 2003, 6:345-35 I.

30. Robertson AK, Zhou X, Strandvik B, Hansson GK: Severe hypercholesterolaemia leads to strong Th2 responses to an exogenous antigen. Scand J Immunol 2004, 59:285-293.

31. Stokes KY, Cooper D, Tailor A, Granger DN: Hypercholesterolemia promotes inflammation and microvascular dysfunction: role of nitric oxide and superoxide. Free Radic Biol Med 2002, 33:1026-1036.

32. Portincasa P, Di Ciaula A, Vendemiale G, Palmieri V, Moschetta A Vanberge-Henegouwen GP, Palasciano G: Gallbladder motility and cholesterol crystallization in bile from patients with pigment and cholesterol gallstones. Eur J Clin Invest 2000, 30:317-24.

33. Nagorna-Stasiak B: Effect of cholesterol on intestinal motility in rabbits in chronic experiments. Pol Arch Weter 1987, 24:445-455. [Polish]

34. Szilvassy Z, Sari R, Nemeth J, Nagy I, Csati S, Lonovics J: Improvement of nitrergic relaxation by farnesol of the sphincter of Oddi from hypercholesterolaemic rabbits. Eur J Pharmacol 1998, 353:75-78.

35. Herman JR, Bass P: Altered carbachol-induced contractile responses of rat jejunal smooth muscle following local myenteric plexus ablation. Dig Dis Sci 1990, 35: I |46-I I 52.

36. De Man JG, Moreels TG, De Winter BY, Bogers JJ, Van Marck EA, Herman AG, Pelckmans PA: Disturbance of the prejunctional modulation of cholinergic neurotransmission during chronic granulomatous inflammation of the mouse ileum. $\mathrm{Br} J$ Pharmacol 2001, 133:695-707.

37. Galligan Jj: Nerve terminal nicotinic cholinergic receptors on excitatory motoneurons in the myenteric plexus of guinea pig intestine. J Pharmacol Exp Ther 1999, 291:92-98.

38. Galligan JJ, Pan H, Messori E: Signalling mechanism coupled to 5hydroxytryptamine 4 receptor-mediated facilitation of fast synaptic transmission in the guinea-pig ileum myenteric plexus. Neurogastroenterol Motil 2003, I 5:523-529.

39. Iversen HH, Wiklund NP, Olgart C, Gustafsson LE: Nerve stimulation-induced nitric oxide release as a consequence of muscarinic MI receptor activation. Eur J Pharmacol 1997, 33I:213-219.

40. Kilbinger $H$, Nafziger $M$ : Two types of neuronal muscarine receptors modulating acetylcholine release from guinea-pig myenteric plexus. Naunyn Schmiedebergs Arch Pharmacol 1985, 328:304-309.

41. Kurjak M, Sattler D, Schusdziarra V, Allescher HD: Characterization of prejunctional and postjunctional muscarinic receptors of the ascending reflex contraction in rat ileum. J Pharmacol Exp Ther 1999, 290:893-900.

42. Briejer MR, Bosmans JP, Van Daele P, Jurzak M, Heylen L, Leysen JE, Prins NH, Schuurkes JA: The in vitro pharmacological profile of prucalopride, a novel enterokinetic compound. Eur J Pharmacol 200I, 423:71-83.

43. Prins NH, Akkermans LM, Lefebvre RA, Schuurkes JA: 5-HT(4) receptors on cholinergic nerves involved in contractility of canine and human large intestine longitudinal muscle. $\mathrm{Br} J$ Pharmacol 2000, I 3 1:927-932.

44. Graf S, Sarna SK: 5-HT-induced jejunal motor activity: enteric locus of action and receptor subtypes. Am J Physiol 1996 270:G992-1000

45. Grider JR: Neurotransmitters mediating the intestinal peristaltic reflex in the mouse. J Pharmacol Exp Ther 2003 307:460-467.

46. Foxx-Orenstein AE, Kuemmerle JF, Grider JR: Distinct 5-HT receptors mediate the peristaltic reflex induced by mucosal stimuli in human and guinea pig intestine. Gastroenterology | 996, I I I:| |28I-I290.

47. Grider JR, Foxx-Orenstein AE, Jin JG: 5-Hydroxytryptamine receptor agonists initiate the peristaltic reflex in human, rat and guinea pig intestine. Gastroenterology 1998, I I 5:370-380

48. Linnik MD, Butler BT, Elsea SH, Ahmed NK: Analysis of neurogenic contractions induced by ML-I035 and other benza- mides in the guinea-pig non-stimulated isolated ileum. Pharm Pharmacol 1994, 46:491-496.

49. Schikowski A, Thewissen M, Mathis C, Ross HG, Enck P: Serotonin type-4 receptors modulate the sensitivity of intramural mechanoreceptive afferents of the cat rectum. Neurogastroenterol Motil 2002, I 4:22 I-227.

50. Sanger G]: Three different ways in which 5-hydroxytryptamine can affect cholinergic activity in guinea-pig isolated ileum. J Pharm Pharmacol 1985, 37:584-586.

\section{Pre-publication history}

The pre-publication history for this paper can be accessed here:

http://www.biomedcentral.com/1471-230X/6/8/prepub
Publish with Bio Med Central and every scientist can read your work free of charge

"BioMed Central will be the most significant development for disseminating the results of biomedical research in our lifetime. "

Sir Paul Nurse, Cancer Research UK

Your research papers will be:

- available free of charge to the entire biomedical community

- peer reviewed and published immediately upon acceptance

- cited in PubMed and archived on PubMed Central

- yours - you keep the copyright 